\title{
Corticosteroids and Surfactant Change Lung Function and Protein Leaks in the Lungs of Ventilated Premature Rabbits
}

\author{
Machiko Ikegami, David Berry, Tarek ElKady, Andrea Pettenazzo, Steven Seidner, and Alan Jobe \\ Department of Pediatrics, Harbor-UCLA Medical Center, Torrance, California 90509
}

\begin{abstract}
Fetal rabbits were treated with corticosteroids by maternal administration for $48 \mathrm{~h}$ before delivery at $27 \mathrm{~d}$ gestational age. The treated and control rabbits were placed on ventilator-plethysmographs so that ventilation could be adjusted by regulation of tidal volumes to $10-13 \mathrm{ml} / \mathrm{kg}$ body $\mathrm{wt}$. $\left[{ }^{125} \mathrm{I}\right]$ albumin was mixed with fetal lung fluid at birth, alternate rabbits from each litter were treated with Surfactant-TA, and [ ${ }^{131}$ I]albumin was injected intravascularly. The movement of the labeled albumins into and out of the alveolar wash and lung tissue was measured after 30 min of ventilation. Corticosteroid treatment (total dose, $0.2 \mathrm{mg} /$ $\mathrm{kg}$ betamethasone) significantly decreased the protein leak across the endothelium $(P<0.001)$ but increased the protein leak across the epithelium $(P<0.001)$. Surfactant treatment decreased both the endothelial and epithelial leaks, and the combination of surfactant and corticosteroid treatments decreased endothelial leaks to $29 \%$ of control values and increased compliance more than either treatment alone. The 48-h corticosteroid treatment did not increase alveolar surfactant pool sizes. Corticosteroids significantly changed lung protein leaks independently of surfactant, and improved the response of the preterm lung to surfactant treatments.
\end{abstract}

\section{Introduction}

The maternal administration of corticosteroids given at least 48 $h$ before delivery decreases the incidence and severity of respiratory distress syndrome (RDS) ${ }^{1}$ in preterm infants $(1,2)$. A major effect of corticosteroids on the developing lung is thought to result from stimulation of surfactant synthesis $(3,4)$, because a deficiency of surfactant is central to the pathophysiology of RDS (5). Numerous experiments in animals document that maternally administered corticosteroids will increase choline incorporation rates into fetal lungs and lung explants (6). Corticosteroids stimulate palmitic acid synthesis in the fetal lung and cause glycogen to disappear from type II cells, indicating effects on surfactant precursor pools $(7,8)$. Corticosteroids also cause a growth arrest of the fetal lung and stimulate alveolarization $(9,10)$. Corticosteroids change the mechanical properties of the

Address reprint requests to Machiko Ikegami, M.D., Harbor-UCLA Medical Center, Bldg. A-17, 1000 West Carson Street, Torrance, CA 90509.

Received for publication 19 June 1986 and in revised form $15 \mathrm{De}$ cember 1986

1. Abbreviation used in this paper: RDS, respiratory distress syndrome.

J. Clin. Invest.

(c) The American Society for Clinical Investigation, Inc.

0021-9738/87/05/1371/08 \$1.00

Volume 79, May 1987, 1371-1378 fetal lung as assessed by static pressure-volume curves, an effect that may be independent of changes in surfactant pools (11). While antenatal dexamethasone reduces the incidence and severity of RDS in preterm monkeys, the effects are not confined to changes in surfactant pools $(12,13)$.

Pulmonary edema, protein leaks, and small airway epithelial damage are characteristic of the lungs of ventilated infants and animals with RDS $(14,15)$. The soluble proteins that enter the airways can interact with the already inadequate amounts of surfactant and further compromise surfactant function (16). Corticosteroids were shown to decrease the permeability of the postnatal rat lung to low molecular weight drugs and to accelerate renal functional maturation in fetal lambs $(17,18)$. Independent of their effect on lung maturation, corticosteroids have other effects on preterm infants such as decreasing the incidence of necrotizing enterocolitis, ductus arteriosus, and serum electrolyte abnormalities $(19,20)$. These and other responses in preterm animals and infants likely are mediated at least in part by effects on the endothelium and/or epithelium. Therefore, we asked if corticosteroids could change the protein leaks characteristic of the preterm ventilated lung. Because surfactant treatment of RDS appears to be helpful, there was a secondary question of what the effect of a surfactant treatment on the lung previously treated with corticosteroids would be.

\section{Methods}

Corticosteroid treatments. 11 pregnant New Zealand White rabbits received intramuscular injections of $0.1 \mathrm{mg}$ betamethasone per $\mathrm{kg}$ (Celestone Soluspan, Schering Corp., Kenilworth, NJ) on gestational days 25 and 26,48 and $24 \mathrm{~h}$ before delivery of the fetuses on day 27 of gestation. Eight other does received vehicle injections only. A second group of eight pregnant does received $0.1 \mathrm{mg}$ betamethasone per $\mathrm{kg}$ by intramuscular injection and $0.1 \mathrm{mg}$ dexamethasone per $\mathrm{kg}$ by intravascular injection $4 \mathrm{~h}$ before delivery of the fetuses. Eight pregnant does received vehicle injections at the same time before delivery.

Delivery of fetuses. The does received intravenous pentobarbital to achieve light anesthesia and oxygen by face mask. The abdominal wall was anesthetized with $1 \%$ lidocaine, and the uterus was exposed. Fetal rabbits were sequentially removed and weighed, and a tube made from an 18-gauge needle was tied into the trachea of each rabbit via a neck incision. Alternate rabbits received $120 \mu \mathrm{l}$ of $0.9 \%$ saline containing 1 $\mu \mathrm{Ci}\left[{ }^{125} \mathrm{I}\right]$ albumin $(\sim 2 \mu \mathrm{g}$ protein) or $120 \mu \mathrm{l}$ saline containing the labeled albumin plus $2.25 \mathrm{mg}$ Surfactant-TA. The surfactant was prepared from beef lung and kindly provided by the Tokyo Tanabe Co., Tokyo, Japan. This surfactant has been extensively characterized and was effective in clinical trials for the treatment of RDS (21). The tracheal tube of each rabbit then was connected to a 0.5 I anesthesia bag delivering $100 \%$ oxygen, and the rabbit was ventilated with initial peak pressures of 35 $\mathrm{cmH}_{2} \mathrm{O}$ and inspiratory times of about $0.5 \mathrm{~s}$ for about five breaths until satisfactory chest motion occurred. The rabbit then was transferred to the ventilator. The rabbit received a $0.2-\mathrm{ml}$ intravascular injection of 1 $\mu \mathrm{Ci}\left[{ }^{131} \mathrm{I}\right]$ albumin in $0.9 \% \mathrm{NaCl}$ via the external jugular vein. The time between delivery and placement on the ventilator averaged $2 \mathrm{~min}$, and about $1 \mathrm{~min}$ more was required to complete the intravascular injection. 
Ventilation of rabbits. The rabbits were ventilated in a series of 10 plexiglas boxes that were maintained at $37^{\circ} \mathrm{C}$ with a circulating water bath. The ventilatory circuit was modified from that described by Lachmann et al. (22) to be a rebreathing circuit that permitted the peak pressures to be independently varied for each rabbit (Fig. 1.). Soda lime was placed in a cartridge to absorb $\mathrm{CO}_{2}$ just proximal to the entrance of the endotracheal tube into the ventilator circuit. A pressure-limited infant ventilator (Sechrist Industries, Inc., Anaheim, CA) was used to drive the 10 ventilator circuits. Ventilator settings were a rate of 40 breaths/min with a 1:1 inspiratory-to-expiratory time ratio, $100 \%$ oxygen, and no positive end expiratory pressure. Tidal volumes delivered to each rabbit were measured with a pneumotachygraph connected to the plexiglas box. The pressure changes across the pneumotachygraph were measured with a differential pressure transducer (Validyne Engineering Corp., Northridge, CA) and electronically integrated to volumes. Knowing the weight of each rabbit, the peak inspiratory pressure delivered to each rabbit was adjusted such that the tidal volume would be between 10 and $13 \mathrm{ml} / \mathrm{kg}$. Volume measurements and any necessary pressure adjustments were made at least every $5 \mathrm{~min}$ for each rabbit. Compliance was calculated by dividing tidal volume per kilogram body weight by the peak inspiratory pressure. $30 \mathrm{~min}$ after the initiation of ventilation, each rabbit was disconnected from the ventilator and killed with an intracerebral injection of lidocaine that stopped the heart immediately. The chest was rapidly opened and blood was drawn into a heparinized syringe from the heart. Blood $\mathrm{PCO}_{2}$ and $\mathrm{pH}$ values were measured, and blood was saved to measure radiolabeled albumin and hemoglobin. The sex of each rabbit was determined by examination of the gonads (23).

Processing of lungs. Following sacrifice, the lungs of each rabbit were

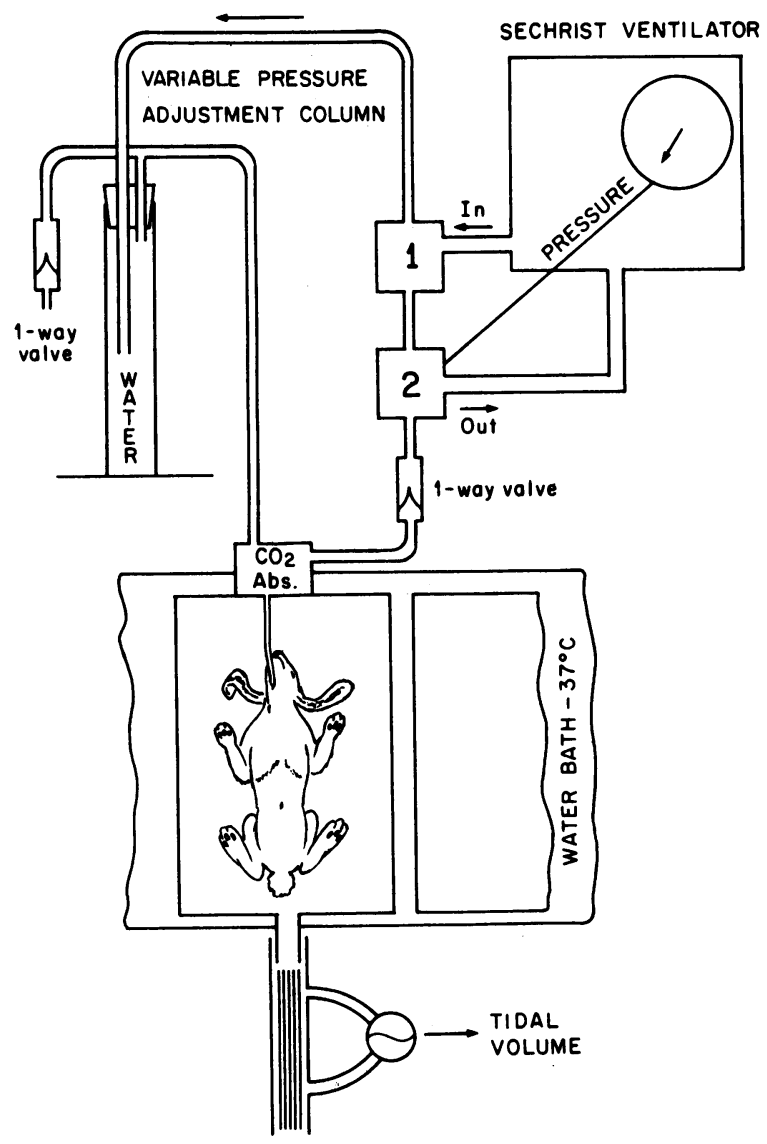

Figure 1. Ventilator-plethysmograph used to ventilate the rabbits. The rabbits were placed in a series of 10 plexiglas boxes, each box having the circuit connected to mixing boxes 1 and 2 . The one-way valves were Heimlich chest tube drainage valves. Pressure was adjusted in each box with the water column to regulate tidal volumes. washed with $0.9 \% \mathrm{NaCl}$ via the endotracheal tube. Sufficient saline to distend the lungs $(2-3 \mathrm{ml})$ was washed in and out of the lungs three times, and the washes were repeated with 4 aliquots of saline. All five washes were pooled. The lungs were removed and weighed. The ${ }^{125} \mathrm{I}$ and ${ }^{131}$ I radioactivity associated with the alveolar washes, lung tissue, and blood were measured. The lungs were homogenized in water and hemoglobin was measured on cleared supernatants and hemolyzed aliquots of blood (15). The hemoglobin associated with the lung homogenates was assumed to be from intravascular blood, and the blood-associated radioactivity was subtracted from that measured for each lung (15). Labeled albumin recoveries were expressed as percent of injected dose.

Aliquots of the alveolar washes and lung homogenates were extracted with chloroform/methanol (24). The saturated phosphatidylcholine was recovered from lipid extracts by column chromatography after oxidation with $\mathrm{OsO}_{4}(25)$. Phosphatidylcholine was separated from other lipids by thin-layer chromatography and quantified by phosphate assay (26).

Radiolabeled albumins. Monomer standard bovine serum albumin (Miles Laboratories, Inc., Elkhart, IN) was iodinated with either ${ }^{131} I$ or ${ }^{125}$ I using chloramine $\mathrm{T}$. The albumin solutions were extensively dialyzed to remove unbound albumin, and the percent bound was checked by trichloroacetic acid precipitation (15).

Data analysis. Rabbits were excluded from analysis for terminal pH values $<7.0$ and/or $\mathrm{PCO}_{2}$ values $>60 \mathrm{mmHg}$. Results are reported as means $\pm \mathrm{SE}$, and comparisons were by analysis of variance followed by the Student Newman-Keuls multiple comparison procedure. Because protein leaks increased as ventilatory pressure needed to achieve the desired tidal volume increased, measurements of $\left[{ }^{125} \mathrm{I}\right]$ albumin and $\left[{ }^{131} \mathrm{I}\right]$ albumin recoveries were analyzed by linear regression versus the mean peak inspiratory pressures used to ventilate the rabbits. Mean peak inspiratory pressures were calculated from pressures at 5, 10, 20, and 30 min. Lines were fit by the method of least squares, and regression lines were compared by an analysis of covariance. Significance was accepted for $P<0.05$.

\section{Results}

Description of animals (48-h treatment). Corticosteroids had significant effects on body weights of rabbits treated for $48 \mathrm{~h}$ (Table I). However, the saturated phosphatidylcholine recovery in the alveolar washes after $30 \mathrm{~min}$ of ventilation was not increased by corticosteroid treatment. Corticosteroid therapy caused abortion in 2 of 10 treated does, and 3 of the remaining does began delivering fetuses while under anesthesia at $27 \mathrm{~d}$ gestational age. In one other corticosteroid-treated doe, six of nine fetuses were dead. No such fetal deaths or early deliveries occurred in control litters. When the exclusion criteria were applied to the terminal blood gas values, seven animals (one or two in each group) were dropped from the analysis. Six other animals were excluded from the analysis because they developed pneumothoraces and died before $30 \mathrm{~min}$ of age. The numbers of rabbits given in the tables are the numbers in each group included in the final analysis.

We were able to successfully and comparably ventilate the rabbits as assessed by the terminal $\mathrm{pH}$ and $\mathrm{PCO}_{2}$ values by regulating tidal volumes per kilogram. The rabbits treated with corticosteroids plus surfactant had significantly larger mean tidal volumes (Table I), because we did not respond quickly enough to their improving compliances and lower pressure needs (Fig. 2). The other groups had comparable mean tidal volumes. The peak ventilatory pressures of about $22 \mathrm{~cm} \mathrm{H}_{2} \mathrm{O}$ were comparable for the steroid and control rabbits not treated with surfactant and calculated compliance values were not different. Surfactant treatments of the control rabbits significantly decreased mean peak pressure to $18.4 \mathrm{~cm} \mathrm{H}_{2} \mathrm{O}$. The combination of surfactant and corticosteroid treatments resulted in a large decrease in peak 


\begin{tabular}{|c|c|c|c|c|c|}
\hline & $\begin{array}{l}\text {-Steroids } \\
\text {-Surfactant }\end{array}$ & $\begin{array}{l}\text { +Steroids } \\
\text {-Surfactant }\end{array}$ & $\begin{array}{l}\text {-Steroids } \\
\text { +Surfactant }\end{array}$ & $\begin{array}{l}\text { +Steroids } \\
\text { +Surfactant }\end{array}$ & $P<0.05$ \\
\hline Number & 26 & 26 & 30 & 29 & \\
\hline Body weight $(g)$ & $38.0 \pm 1.0$ & $27.9 \pm 1.1$ & $36.8 \pm 0.9$ & $27.7 \pm 1.1$ & $1,3>2,4$ \\
\hline $\mathrm{pH}$ at $30 \mathrm{~min}$ & $7.46 \pm 0.02$ & $7.38 \pm 0.02$ & $7.45 \pm 0.02$ & $7.41 \pm 0.03$ & - \\
\hline $\mathrm{PCO}_{2}$ at $30 \mathrm{~min}(\mathrm{mmHg})$ & $37.0 \pm 1.3$ & $39.0 \pm 1.7$ & $37.1 \pm 2.0$ & $36.5 \pm 2.1$ & - \\
\hline Mean peak inspiratory pressure $\left(\mathrm{cm} \mathrm{H}_{2} \mathrm{O}\right)$ & $22.9 \pm 1.0$ & $20.9 \pm 1.1$ & $18.4 \pm 0.5$ & $13.8 \pm 0.4$ & $1,2,3>4 ; 1>3$ \\
\hline Mean tidal volume $(\mathrm{ml} / \mathrm{kg})$ & $11.5 \pm 0.4$ & $12.8 \pm 0.4$ & $12.1 \pm 0.3$ & $13.8 \pm 0.5$ & $4>1,3$ \\
\hline Saturated phosphatidylcholine in AW $(\mu \mathrm{mol} / \mathrm{kg})$ & $3.1 \pm 0.6$ & $2.7 \pm 0.3$ & $27.7 \pm 1.3$ & $41.8 \pm 2.2$ & $4>3>1,2$ \\
\hline Saturated phosphatidylcholine in $\mathrm{L}(\mu M / \mathrm{kg})$ & $71 \pm 5$ & $62 \pm 3$ & $74 \pm 5$ & $78 \pm 3$ & - \\
\hline Male/female & $14 / 12$ & $16 / 10$ & $19 / 11$ & $11 / 18$ & - \\
\hline
\end{tabular}

AW, alveolar wash; L, lung tissue after alveolar wash.

pressure to about $14 \mathrm{~cm} \mathrm{H}_{2} \mathrm{O}$. There were no differences in any of the mean values in Table I when the data were analyzed by the sex of the rabbits.

Protein leaks from vascular space to lungs (48-h treatment). The intravascularly injected [ $\left.{ }^{131} \mathrm{I}\right]$ albumin could be used to indicate different protein leaks into the lungs of the corticosteroid and control animals only if comparable amounts of the label remained in the intravascular space during the 30-min measurement. In control experiments we found comparable blood volumes and percent recoveries of the intravascular albumin in the organs and carcass at sacrifice in corticosteroid and control rabbits. The total recoveries were 41.8 and $37.3 \%$, respectively, for control and corticosteroid-treated rabbits, indicating very similar amounts of the injected isotope remained in the intravascular space and thus had a chance to leak into the lungs. Large leaks present in control lungs were decreased significantly by both corticosteroids and surfactant (Table II). The leak of $\left[{ }^{131} \mathrm{I}\right]$ albumin from the vascular space into the lung tissue and alveolar wash decreased by $\sim 30 \%$ with corticosteroid treatment, whereas surfactant alone decreased the leak to $\sim 50 \%$ of control values. The combined treatments decreased the leak into the alveoli to $13 \%$ of control values and into the total lung (alveolar wash plus lung tissue) to $29 \%$ of the control values. The mean

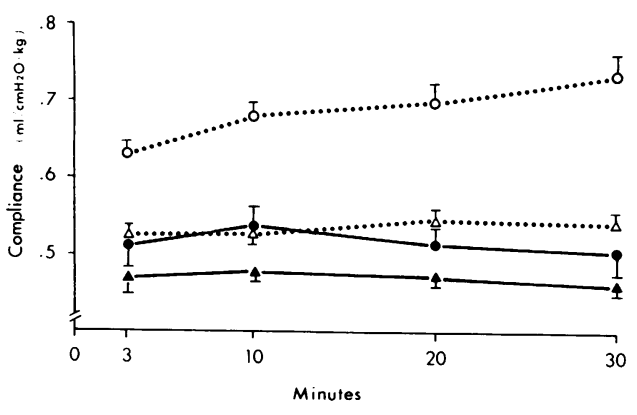

Figure 2. Compliance values of rabbits. Mean \pm SE compliance values were calculated from the measured tidal volumes and peak inspiratory pressures used to ventilate the rabbits. ( $\triangle$ ) Rabbits not treated with corticosteroids or surfactant $(n=26) ;(\bullet)$ rabbits treated with corticosteroids $(n=26)$; $(\Delta)$ rabbits treated with surfactant $(n=30)$; (0) rabbits treated with surfactant and corticosteroids $(n=29)$. Values at 30 min were significantly different between the corticosteroid-plus-surfactant-treated rabbits and all other groups $(P<0.01)$, and between the control rabbits and surfactant-treated rabbits $(P<0.05)$. pressures required to ventilate the control and corticosteroid groups were similar but the protein leak was decreased; therefore, corticosteroids decreased the vascular to lung protein leak independently of a pressure effect. This conclusion was supported by the correlations of protein leak from the vascular space to the lungs with the peak inspiratory pressures needed to ventilate the rabbits (Fig. 3). The combined data for rabbits with or without surfactant treatments fell along similar regression lines. Thus, surfactant decreased the protein leak in proportion to the effect of surfactant on ventilatory pressures. The corticosteroid treatment decreased the slope of the regression curves for leak versus ventilatory pressures in the alveolar washes and total lungs of the rabbits. The results were not changed if the surfactant-treated rabbits were excluded from the analysis.

Protein leaks from airways and alveoli (48- $h$ treatment). All groups of rabbits lost large amounts of $\left[{ }^{125} \mathrm{I}\right]$ albumin from the lungs over the 30 -min period of ventilation (Table II). Whereas the mean values for the recovery of $\left[{ }^{125} \mathrm{I}\right]$ albumin from the airways and alveoli did not change significantly from control values in rabbits treated with corticosteroids, the numerical values suggest that more labeled albumin was lost from the airways and alveoli to the lung tissue and that there was less total recovery in the lungs of corticosteroid-treated rabbits. This impression was validated by the regression curves of $\left[{ }^{125} \mathrm{I}\right]$ albumin loss versus ventilatory pressures (Fig. 4). The slopes of the curves for alveolar wash and total lung for the corticosteroid-treated rabbits were not different from the slopes for the control rabbits; however, the curves were different by an analysis of covariance. Overall corticosteroid treatment increased the loss of protein from the lungs. Surfactant treatments decreased the protein leak in proportion to the effect of surfactant on ventilatory pressures. The combination of surfactant and corticosteroid treatments did not change the increased leak caused by the corticosteroids. The differences in leak following corticosteroid treatment could be demonstrated using either the data for rabbits not treated with surfactant or the pooled data that included the surfactant-treated rabbits. No sex-dependent differences in any of the protein leak measurements were noted.

Results after $4 h$ of corticosteroids. The rabbits delivered from the does treated with corticosteroids $4 \mathrm{~h}$ before delivery had significantly lower $\mathrm{pH}$ values at $30 \mathrm{~min}$ of age than did the control rabbits (Table III). Tidal volumes and $\mathrm{PCO}_{2}$ values were comparable, indicating comparable ventilation. Therefore, corticosteroid treatments shortly before delivery caused a significant 


\begin{tabular}{|c|c|c|c|c|c|}
\hline & $\begin{array}{l}\text {-Steroids } \\
\text {-Surfactant }\end{array}$ & $\begin{array}{l}\text { +Steroids } \\
\text {-Surfactant }\end{array}$ & $\begin{array}{l}\text {-Steroids } \\
\text { +Surfactant }\end{array}$ & $\begin{array}{l}\text { +Steroids } \\
\text { +Surfactant }\end{array}$ & $P<0.05$ \\
\hline \multicolumn{6}{|c|}{$\%$ Recovery of intravascular ${ }^{131} \mathrm{I}$-albumin } \\
\hline AW & $5.4 \pm 0.8$ & $3.3 \pm 0.5$ & $2.0 \pm 0.3$ & $0.7 \pm 0.2$ & $1>2>3>4$ \\
\hline $\mathbf{L}$ & $3.5 \pm 0.3$ & $2.9 \pm 0.2$ & $2.4 \pm 0.2$ & $1.8 \pm 0.2$ & $1>2,3>4$ \\
\hline$A W+L$ & $8.7 \pm 1.0$ & $5.9 \pm 0.6$ & $4.4 \pm 0.3$ & $2.5 \pm 0.3$ & $1>2>3>4$ \\
\hline \multicolumn{6}{|c|}{ \% Recovery of intratracheal ${ }^{125} \mathrm{I}$-albumin } \\
\hline AW & $41.2 \pm 2.4$ & $35.6 \pm 2.6$ & $59.6 \pm 1.7$ & $55.5 \pm 2.0$ & $3,4>1,2$ \\
\hline $\mathbf{L}$ & $16.4 \pm 0.9$ & $19.5 \pm 0.9$ & $16.5 \pm 0.9$ & $19.4 \pm 0.9$ & - \\
\hline$A W+L$ & $57.9 \pm 2.6$ & $55.1 \pm 2.3$ & $76.1 \pm 1.4$ & $74.8 \pm 2.2$ & $3,4>1,2$ \\
\hline
\end{tabular}

AW, alveolar wash; L, lung tissue after alveolar wash, corrected for intravascular blood.

metabolic acidosis. Corticosteroid treatment did not alter the peak pressures required to achieve the desired tidal volumes, whereas surfactant significantly and comparably decreased the pressures in both groups. There were no effects of corticosteroids on body weight or saturated phosphatidylcholine pool sizes.

The protein leak measurements were not changed by the corticosteroid treatment (Table IV). Whereas surfactant mediated effects similar to those measured in the rabbits treated with corticosteroids for $48 \mathrm{~h}$ were seen, the short-term corticosteroid treatment did not augment the surfactant effects. The protein leak variables correlated with ventilatory pressures, but corticosteroids did not change the relationships (Fig. 5).

\section{Discussion}

The protein leak abnormalities characteristic of the pretermventilated lung were measured previously in the lamb (15). Whereas we recently demonstrated that surfactant treatments will decrease protein leak in the ventilated rabbit, these studies were compromised by our inability to regulate ventilation for each rabbit (27). The ventilator that we have built permitted us to regulate ventilation by adjusting the tidal volumes of each rabbit. While we do not know the functional residual capacity of each rabbit, and the dynamics of ventilation change with surfactant treatments (28), ventilation was equivalent as assessed by $\mathrm{PCO}_{2}$ values in the different groups of rabbits. Because blood was taken for $\mathrm{pH}$ and $\mathrm{PCO}_{2}$ measurements after sacrifice and the blood was from the right and/or left ventricles, $\mathrm{PO}_{2}$ values were not reported. However, the surfactant-treated rabbits were more pink, indicating improved oxygenation relative to the groups not treated with surfactant. The ventilated preterm rabbit model permits the investigator to study a large number of animals. However, results can be easily biased if sufficient litters are not studied, because the variation in responses of rabbits between litters exceeded the variation within each litter. We studied rabbits from at least eight litters for each treatment group.

The effects of corticosteroids on lung maturation in the rabbit have been studied following direct fetal injection or maternal administration (6). Direct fetal administration of corticosteroids caused dramatic morphologic maturation of type II cells (29, 30), increased lung stability (3), and caused a 4.6-fold increase in alveolar phosphatidylcholine (31). However, maternal ad-
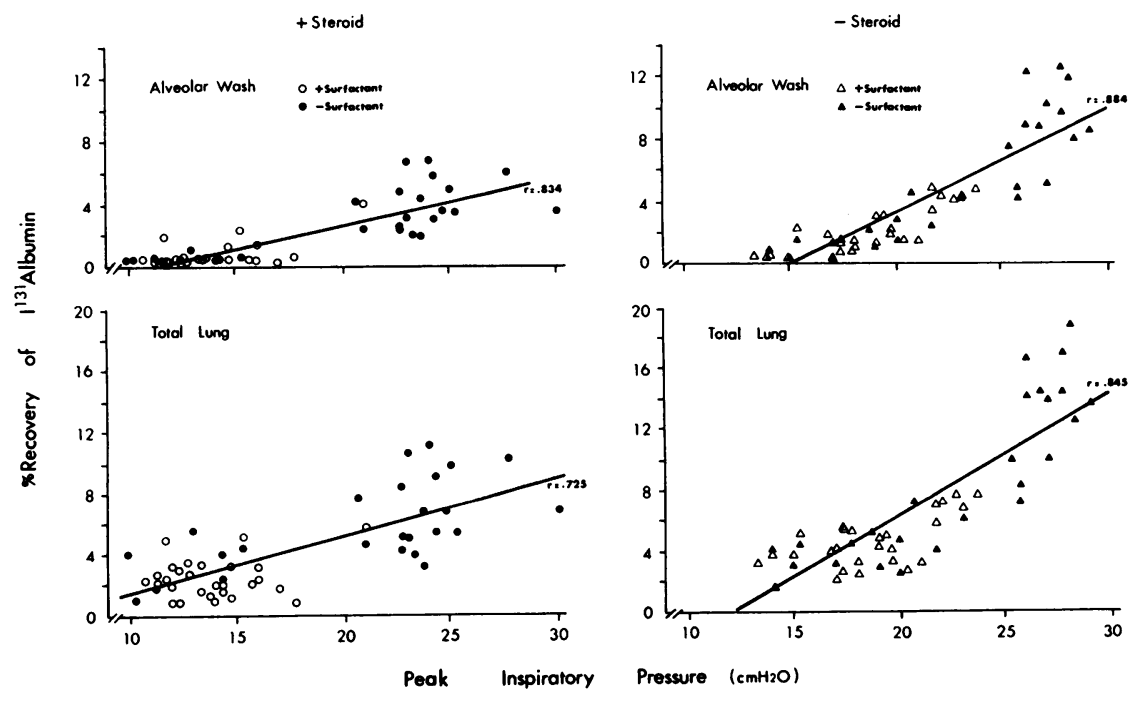

Figure 3. Correlations of mean peak inspiratory pressures and leak of ${ }^{131} \mathrm{I}$-albumin from the vascular space into alveolar washes and total lung (alveolar washes + lung tissue corrected for intravascular blood). The regression lines are for the combined data for animals not treated and treated with surfactant. The regression lines for corticosteroid-treated rabbits were significantly different from the lines for the rabbits not treated with corticosteroids (alveolar wash, F $=50, P<0.001$; total lung, $\mathrm{F}=30, P$ $<0.001$ ). 

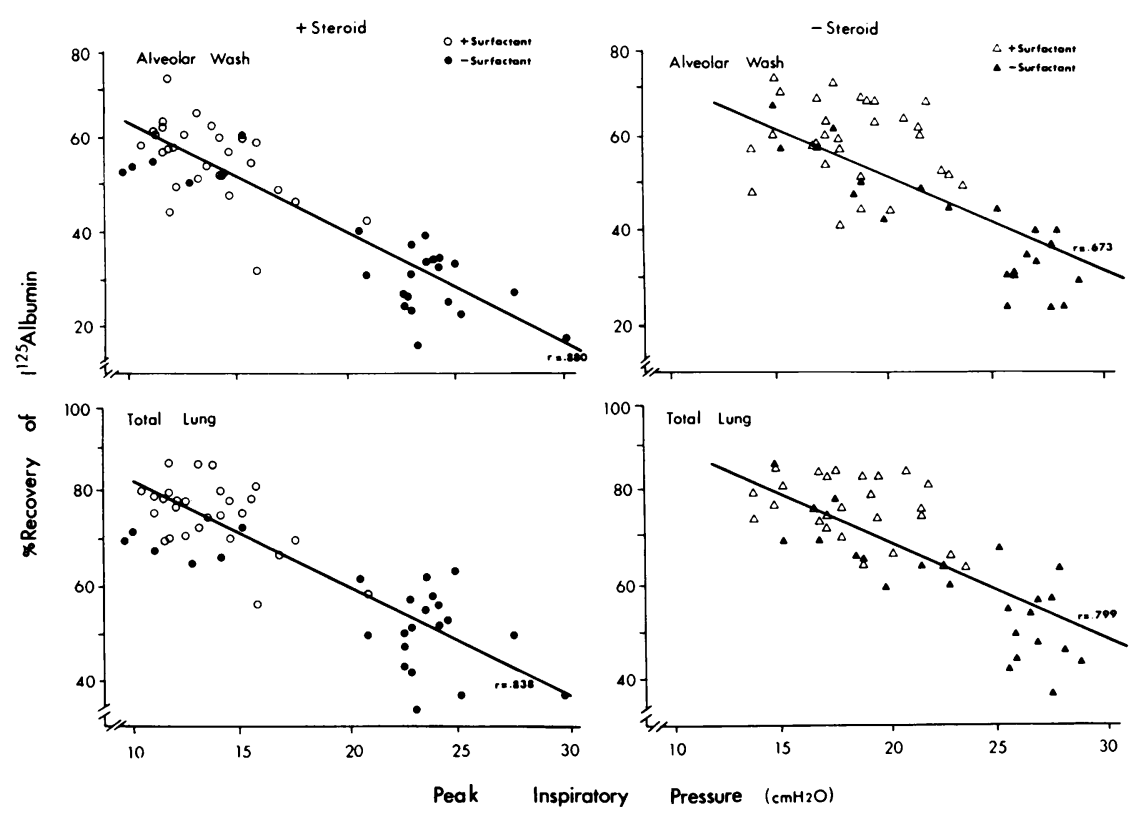

Figure 4. Correlations of mean peak inspiratory pressures with recovery of [ $\left.{ }^{125} \mathrm{I}\right] \mathrm{albumin}$ in the alveolar washes and total lungs. Regression lines are for combined data for animals not treated and treated with surfactant. The regression lines for corticosteroid-treated rabbits were significantly different from the lines for rabbits not treated with corticosteroids (alveolar wash, $\mathrm{F}=53, P<0.001 ;$ total lung, $\mathrm{F}=25$, $P<0.001)$.

ministration of $0.4 \mathrm{mg} / \mathrm{kg}$ betamethasone caused less than a twofold increase in alveolar total and saturated phosphatidylcholine, and higher doses resulted in fetal death $(23,31)$. The total dose of $0.2 \mathrm{mg} / \mathrm{kg}$ betamethasone chosen for this study was the lowest dose reported to effect lung maturation in the rabbit following maternal administration (32). This dose was less than the $\sim 0.2 \mathrm{mg} / \mathrm{kg}$ dose of dexamethasone given every $12 \mathrm{~h}$ for 4 doses to the human to prevent RDS (2). Of course fetal growth rates differ significantly in the human and rabbit so that the drug doses are not strictly comparable. Despite the low dose of corticosteroids, fetal death, abortion, and significant growth retardation occurred. In our study, no increase in surfactant pool size was detected, consistent with the lack of effect of corticosteroids on the peak pressures needed to ventilate the rabbits. The lack of effect on endogenous surfactant pools may in part result from the low dose of corticosteroids used in these protocols. Nevertheless, corticosteroids clearly affected the lungs because surfactant treatment of the corticosteroid-treated rabbits resulted in a significant decrease in peak inspiratory pressures and an increase in compliance relative to the surfactant-treated control group. This result indicated that lung structure was likely mod- ified to permit an enhanced surfactant effect. Mitzner et al. (9) documented structural changes in the preterm monkey lung following $13 \mathrm{~d}$ of corticosteroid treatment that suggested a stimulation of alveolarization. Bunton and Plopper (10) found definite early alveolarization in preterm monkeys following highdose corticosteroid treatments, and Kotas and Avery (3) found a twofold increase in gas volume in $27 \mathrm{~d}$ gestational age fetal rabbits following direct fetal injection with corticosteroids. While these studies involved prolonged and/or high-dose steroid treatments, we found a $50 \%$ increase in lung volume per gram dry lung weight in rabbits treated with the $0.2 \mathrm{mg} / \mathrm{kg}$ corticosteroid dose (33). Our studies in rabbits indicated that corticosteroids "primed" the lung to respond favorably to large exogenously administered doses of surfactant. By analogy, infants with RDS despite having received corticosteroids may have excellent responses to surfactant treatments.

The effect of corticosteroids on lung protein leaks can be interpreted by considering the lung as three compartments: the vascular space, the interstitium here represented by lung tissue, and the airways and alveoli. Protein leaks were large and bidirectional. In control animals not treated with surfactant, 9\%

Table III. Characteristics after $4 \mathrm{~h}$ of Corticosteroids

\begin{tabular}{|c|c|c|c|c|c|}
\hline & $\begin{array}{l}\text {-Steroids } \\
\text {-Surfactant }\end{array}$ & $\begin{array}{l}\text { +Steroids } \\
\text {-Surfactant }\end{array}$ & $\begin{array}{l}\text {-Steroids } \\
\text { +Surfactant }\end{array}$ & $\begin{array}{l}\text { +Steroids } \\
\text { +Surfactant }\end{array}$ & $P<0.05$ \\
\hline Number & 29 & 22 & 31 & 22 & \\
\hline Body weight $(g)$ & $32.4 \pm 0.9$ & $31.8 \pm 1.5$ & $32.0 \pm 1.0$ & $31.0 \pm 1.4$ & - \\
\hline $\mathrm{pH}$ at $30 \mathrm{~min}$ & $7.36 \pm 0.02$ & $7.19 \pm 0.03$ & $7.41 \pm 0.02$ & $7.22 \pm 0.03$ & $1,3>2,4$ \\
\hline $\mathrm{PCO}_{2}$ at $30 \mathrm{~min}$ & $34.7 \pm 1.0$ & $39.2 \pm 1.7$ & $34.0 \pm 1.3$ & $37.1 \pm 2.2$ & - \\
\hline Mean peak inspiratory pressure $\left(\mathrm{cm} \mathrm{H}_{2} \mathrm{O}\right)$ & $25.0 \pm 1.2$ & $24.4 \pm 1.5$ & $19.0 \pm 0.7$ & $18.6 \pm 0.6$ & $1,2>3,4$ \\
\hline Mean tidal volume & $11.5 \pm 0.2$ & $11.3 \pm 0.2$ & $11.4 \pm 0.2$ & $11.3 \pm 0.3$ & - \\
\hline Saturated phosphatidylcholine in AW ( $\mu \mathrm{mol} / \mathrm{kg}$ ) & $3.0 \pm 1.1$ & $3.6 \pm 1.4$ & $28.5 \pm 1.7$ & $30.7 \pm 1.8$ & $3,4>1,2$ \\
\hline Saturated phosphatidylcholine in $\mathrm{L}(\mu \mathrm{mol} / \mathrm{kg})$ & $86 \pm 5$ & $83 \pm 10$ & $104 \pm 6$ & $111 \pm 10$ & - \\
\hline Male/female & $17 / 12$ & $10 / 12$ & $12 / 19$ & $11 / 11$ & - \\
\hline
\end{tabular}

$\mathrm{AW}$, alveolar wash; L, lung tissue after alveolar wash. 


\begin{tabular}{|c|c|c|c|c|c|}
\hline & $\begin{array}{l}\text {-Steroids } \\
\text {-Surfactant }\end{array}$ & $\begin{array}{l}\text { +Steroids } \\
\text {-Surfactant }\end{array}$ & $\begin{array}{l}\text {-Steroids } \\
\text { +Surfactant }\end{array}$ & $\begin{array}{l}\text { +Steroids } \\
\text { +Surfactant }\end{array}$ & $P<0.05$ \\
\hline \multicolumn{6}{|c|}{$\%$ Recovery of intravascular ${ }^{131} \mathrm{I}$-albumin } \\
\hline AW & $7.3 \pm 0.8$ & $7.1 \pm 1.2$ & $2.2 \pm 0.3$ & $1.9 \pm 0.4$ & $1,2>3,4$ \\
\hline L & $4.7 \pm 0.5$ & $4.7 \pm 0.9$ & $1.9 \pm 0.3$ & $1.4 \pm 0.4$ & $1,2>3,4$ \\
\hline$A W+L$ & $11.9 \pm 1.2$ & $11.9 \pm 2.0$ & $4.1 \pm 0.5$ & $3.3 \pm 0.7$ & $1,2>3,4$ \\
\hline \multicolumn{6}{|c|}{$\%$ Recovery of intratracheal ${ }^{125} \mathrm{I}$-albumin } \\
\hline AW & $41.1 \pm 2.8$ & $41.6 \pm 3.0$ & $57.2 \pm 1.9$ & $56.6 \pm 2.6$ & $3,4>1,2$ \\
\hline $\mathbf{L}$ & $21.8 \pm 1.7$ & $23.6 \pm 1.2$ & $23.8 \pm 1.1$ & $24.0 \pm 1.2$ & - \\
\hline$A W+L$ & $62.9 \pm 2.7$ & $64.7 \pm 4.1$ & $81.0 \pm 2.0$ & $79.6 \pm 2.2$ & $3,4>1,2$ \\
\hline
\end{tabular}

AW, alveolar wash; L, lung tissue after alveolar wash, corrected for intravascular blood.

of the total intravascular albumin entered the lungs while $\sim 45 \%$ of the labeled alveolar albumin left the lungs in $30 \mathrm{~min}$. Only a fraction of a percent of either labeled protein should enter or leave the lungs of term or adult animals with $30 \mathrm{~min}$ of ventilation (15). Corticosteroid treatment decreased the vascular-toalveolar protein leak but increased the alveolar-to-vascular leak. These results occurred independently of the pressures needed to ventilate the rabbits. The two primary barriers to protein movement in the lungs are the vascular endothelium and the alveolar epithelium. Protein normally moves across the vascular epithelium and is cleared from the interstitium by lymphatic drainage (34). Corticosteroids changed the vascular endothelium and/or the surface area of the endothelium such that the leak of protein from the vascular space to the lungs decreased. We doubt that the effect of the steroids was to decrease vascular surface area, because comparable doses cause increased lung volumes in preterm rabbits (33). However, no measurements of microvascular surface areas were made in these experiments.

The increased loss of protein from the alveoli and airways indicates that corticosteroids have changed the permeability and/ or surface area of the lung epithelium. Because corticosteroid treatments increase lung volumes $(3,9)$, surface area probably changed. The increased leak therefore could result from any alveolarization induced by corticosteroids. However, other possibilities exist. The corticosteroids may have selectively changed the epithelial barrier independently of surface area effects, making it more permeable to protein. The pulmonary epithelium of the sheep fetus is quite impermeable to protein (35). Following term birth, an adaptive process occurs that results in the rapid clearance of fluid and small molecular weight solutes from the airways and alveoli. Based on measurements made with solutes of different molecular weights and interpreted in terms of a pore size theory, the pores in the pulmonary epithelium increase transiently after birth from $\sim 6 \mu \mathrm{m}$ to $\sim 40 \mu \mathrm{m}$ (35). Possibly this mechanism allowing the newborn to clear fetal lung fluid was "induced" in the preterm lung by corticosteroids.

We also studied rabbits after $4 \mathrm{~h}$ of exposure to corticosteroids to document that the effects of corticosteroids on protein leaks were related to the maturational effects of corticosteroids and not a primarily pharmacologic effect. The does received the same dose of betamethasone by intramuscular injection as was used for the 48-h exposure protocol as well as $0.1 \mathrm{mg} / \mathrm{kg}$ dexamethasone by intravascular injection to assure short-term fetal exposure. Both these synthetic corticosteroids have similar poten-
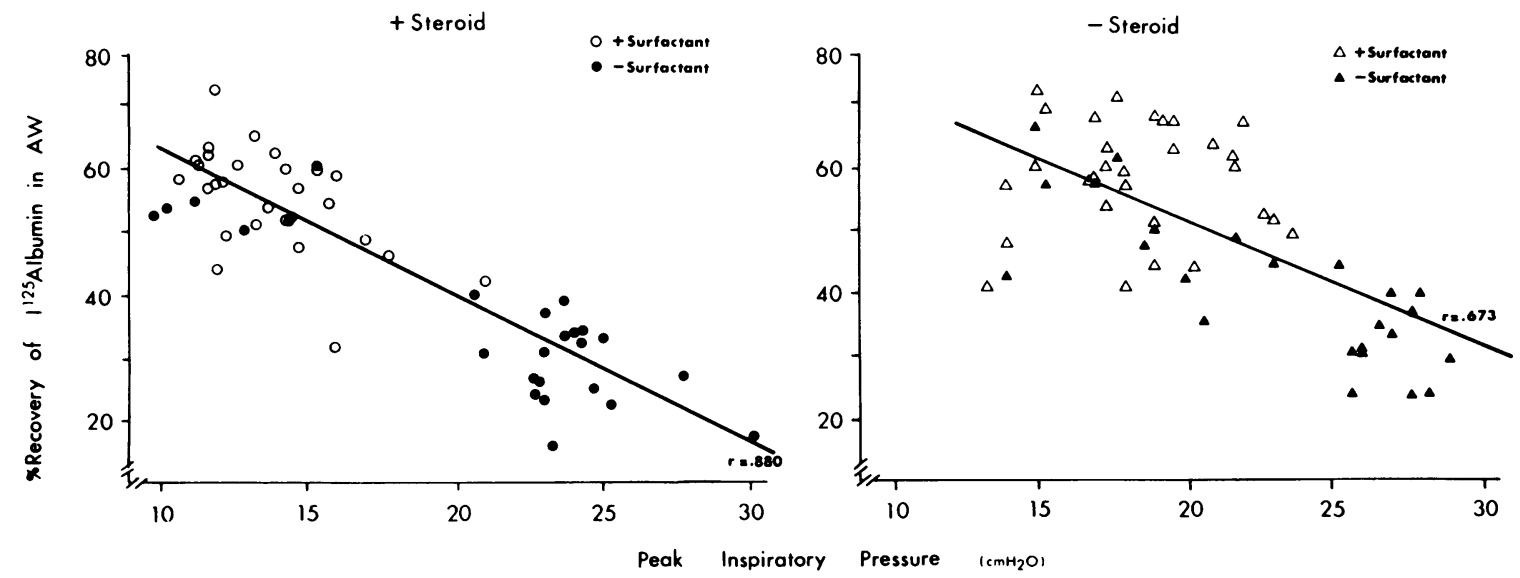

Figure 5. Correlations of mean peak inspiratory pressures and recovery of $\left[{ }^{131} \mathrm{I}\right]$ albumin in alveolar washes $(A W)$ of rabbits exposed to corticosteroids for $4 \mathrm{~h}$ and control rabbits. The regression curves have the same slopes and intercepts, indicating no difference in protein leak. 
cies and induce lung maturation in the rabbit (6). The 4-h corticosteroid treatment caused a metabolic acidosis in the treated animals, but did not effect protein leaks.

Taken together the decreased endothelial leak and the increased epithelial leak following $48 \mathrm{~h}$ of fetal exposure to corticosteroids could influence the evolution of pulmonary edema in the preterm lung unpredictably. The decreased endothelial leak would seem to be highly desirable because interstitial edema would be minimized. On the other hand, an increased epithelial leak, if not a transient adaptive response to birth (35), would allow the interstitial proteins to enter the airways and alveoli. These proteins contribute to the formation of hyaline membranes (14) and may inhibit the surface tension-lowering properties of the surfactant (16).

The protein leaks characteristic of the preterm ventilated lung decrease as gestational age increases (15), and increase as ventilatory pressures needed to normalize $\mathrm{PCO}_{2}$ values increase (36). These two effects probably are reflecting the maturational status of the lungs. Higher ventilatory pressure requirements reflect more immature lungs, but the higher ventilatory pressures likely cause barotrauma and increased leak as well $(14,15,36)$. High frequency ventilation relative to conventional ventilation did not either increase or decrease the bidirectional protein leaks in the preterm lamb lung (37). However, exteriorization of the preterm lamb and apneic distension of the lungs for $1 \mathrm{~h}$ increased the endothelial leak without affecting the epithelial leak (38). These studies demonstrate that corticosteroids influence the protein leak by changing the epithelial and endothelial components of the leak in opposite directions. The protein leak in the preterm-ventilated lung can be manipulated by physical and pharmacologic means. These results imply that strategies can be developed for the care of the preterm infant that may favorably influence pulmonary edema and surfactant function.

The most striking result was the dramatic effect of combined corticosteroid and surfactant treatments on lung function and protein leak. The surfactant treatment decreased the endothelial leak of protein as measured in the lung in control animals to $50 \%$ of control values, whereas this leak decreased to $29 \%$ of control values with the two treatments. In contrast surfactant treatment did not change epithelial leaks of the steroid-treated animals, despite the increased lung volumes resulting from surfactant treatment (21). Also, the epithelial leak of the surfactantplus-corticosteroid-treated animals was not decreased relative to the surfactant treated group despite lower ventilatory pressures. These studies indicate that corticosteroid treatments of the preterm rabbit lung significantly change protein leaks with little demonstrable effect on the surfactant system. The responses of the corticosteroid-treated lungs to exogenously administered surfactant suggest functional improvements related to structural changes in the lungs.

\section{Acknowledgments}

This work was supported by Public Health Service Grant HD-20618, and in part by funding from Consiglio Nazionale delle Ricerche, Grant 85.00746 .56 , in support of Dr. Pettenazzo.

\section{References}

1. Liggins, G. C., and R. N. Howie. 1972. A controlled trial of antepartum glucocorticoid treatment for prevention of the respiratory distress syndrome in premature infants. Pediatrics. 50:515-525.
2. Collaborative Group on Antenatal Steroid Therapy. 1981. Effect of antenatal dexamethasone administration on the prevention of respiratory distress syndrome. Am. J. Obstet. Gynecol. 141:276-287.

3. Kotas, R. V., and M. E. Avery. 1971. Accelerated appearance of pulmonary surfactant in the fetal rabbit. J. Appl. Physiol. 30:358-361.

4. Platzker, A. C. B., J. A. Kitterman, E. J. Mescher, J. A. Clements, and W. H. Tooley. 1975. Surfactant in the lung and tracheal fluid of the fetal lamb and acceleration of its appearance by dexamethasone. Pediatrics. 56:554-561.

5. Avery, M. E., and J. Mead. 1959. Surface properties in relation to atelectasis and hyaline membrane disease. Am. J. Dis. Child. 97:517523.

6. Rooney, S. A. 1985. The surfactant system and lung phospholipid biochemistry. Am. Rev. Resp. Dis. 131:439-460.

7. Mendelson, C. R., and J. M. Snyder. 1985. Effect of cortisol on the synthesis of lamellar body glycerophospholipids in fetal rabbit lung tissue in vitro. Biochim. Biophys. Acta. 834:85-94.

8. Maniscalco, W. M., J. N. Finkelstein, and A. B. Parkhurst. 1985. Dexamethasone increases de novo fatty acid synthesis in fetal rabbit lung explants. Pediatr. Res. 19:1272-1277.

9. Mitzner, W., J. W. C. Johnson, J. Beck, W. London, and D. Sly. 1982. Influence of betamethasone on the development of mechanical properties in the fetal rhesus monkey lung. Am. Rev. Respir. Dis. 25: 233-238.

10. Bunton, T. E., and C. G. Plopper. Triamcinolone-induced structural alterations in the development of the lung of the fetal rhesus macaque. 1984. Am. J. Obstet. Gynecol. 148:203-215.

11. Mitzner, W., J. W. C. Johnson, R. Scott, W. T. London, and A. E. Palmer. 1979. Effect of betamethasone on pressure-volume relationship of fetal rhesus monkey lung. J. Appl. Physiol. 47:377-382.

12. Kessler, D. L., W. E. Truog, J. H. Murphy, S. Palmer, T. A. Standaert, D. E. Woodrum, and W. A. Hodson. 1982. Experimental hyaline membrane disease in the premature monkey. Am. Rev. Respir. Dis. 126:62-69.

13. Liggins, G. C. 1969. Premature delivery of foetal lambs infused with glucocorticoids. J. Endocrinol. 45:515-523.

14. Nilsson, R., G. Grossmann, and B. Robertson. 1980. Bronchiolar epithelial lesions induced in the premature rabbit neonate by short periods of artificial ventilation. Acta Pathol. Microbiol. Scand. 88:359-367.

15. Jobe, A., H. Jacobs, M. Ikegami, and D. Berry. 1985. Lung protein leaks in ventilated lambs: effect of gestational age. J. Appl. Physiol. 58: 1246-1251.

16. Ikegami, M., A. Jobe, and D. Berry. 1986. A protein that inhibits surfactant in respiratory distress syndrome. Biol. Neonate. 50:121-129.

17. Hemberger, J. A., and L. S. Schanker. 1981. Effect of cortisone on permeability of the neonatal rat lung to drugs. Biol. Neonate. 40:99104.

18. Stonestreet, B. S., N. B. Hansen, A. R. Laptook, and W. Oh. 1983. Glucocorticoid accelerates renal functional maturation in fetal lambs. Early Hum. Dev. 8:331-341.

19. Bauer, C. R., J. C. Morrison, W. K. Poole, S. B. Korones, J. J. Boehm, H. Rigatto, and R. D. Zachman. 1984. A decreased incidence of necrotizing enterocolitis after prenatal glucocorticoid therapy. Pediatrics. 73:682-688.

20. Doyle, L. W., W. H. Kitchen, G. W. Ford, A. L. Richards, J. V. Lissenden, and M. M. Ryan. 1986. Effects of antenatal steroid therapy on mortality and morbidity in very low birth weight infants. J. Pediatr. 108:287-292.

21. Fujiwara, T. 1984. Surfactant replacement in neonatal RDS. In Pulmonary Surfactant. B. Robertson, L. M. G. Van Golde, and J. J. Batenburg, editors. Elsevier/North Holland, Amsterdam. 479-503.

22. Lachmann, B., G. Grossman, J. Freyse, and B. Robertson. 1981. Lung-thorax compliance in the artificially ventilated premature rabbit neonate in relation to variations in inspiration: expiration ratio. Pediatr. Res. 15:833-838.

23. Freese, W. B., and M. Hallman. 1983. The effect of betamethasone and fetal sex on the synthesis and maturation of lung surfactant phospholipids in rabbits. Biochim. Biophys. Acta. 750:47-59. 
24. Bligh, E. G., and W. J. Dyer. 1959. A rapid method of total lipid extraction and purification. Can. J. Biochem. Physiol. 37:911-917.

25. Mason, R. J., J. Nellenbogen, and J. A. Clements. 1976. Isolation of disaturated phosphatidylcholine with osmium tetroxide. J. Lipid Res. 17:281-284.

26. Bartlett, G. R. 1959. Phosphorus assay in column chromatography. J. Biol. Chem. 234:466-468.

27. Robertson, B., D. Berry, T. Curstedt, G. Grossmann, M. Ikegami, H. Jacobs, A. Jobe, and S. Jones. 1985. Leakage of protein in the immature rabbit lung: effect of surfactant replacement. Respir. Physiol. 61: 265-276.

28. Lachmann, B., G. Grossmann, R. Nilsson, and B. Robertson. 1981. Effect of supplementary surfactant on in vivo lung mechanics in the premature rabbit neonate. Eur. J. Pediatr. 136:173-179.

29. Wang, N. S., R. V. Kotas, M. E. Avery, and W. M. Thurlbeck. 1971. Accelerated appearance of osmiophilic bodies in fetal lungs following steroid injection. J. Appl. Physiol. 30:362-365.

30. Kikkawa, Y., M. Kaibara, E. K. Motoyama, M. M. Orzalesi, and C. D. Cook. 1971. Morphologic development of fetal rabbit lung and its acceleration with cortisol. Am. J. Pathol. 64:423-433.

31. Rooney, S. A., L. I. Gobran, P. A. Marino, W. M. Maniscalco, and I. Gross. 1979. Effects of betamethasone on phospholipid content, composition, and biosynthesis in the fetal rabbit lung. Biochim. Biophys. Acta. 572:64-76.

32. Ekelund, L., and G. Enhorning. 1985. Glucocorticoids and $\beta$ adrenergic receptor agonists: their combined effect on fetal rabbit lung surfactant. Am. J. Obstet. Gynecol. 152:1063-1067.

33. ElKady, T., and A. Jobe. 1986. The effects of steroids and/or surfactant on lung rupture pressure in preterm rabbits. Pediatr. Res. 20: 428A. (Abstr.)

34. Bland, R. D., T. N. Hansen, C. M. Haberkern, M. A. Bressack, T. A. Hazinski, J. U. Raj, and R. B. Goldberg. 1982. Lung fluid balance in lambs before and after birth. J. Appl. Physiol. 53:992-1004.

35. Egan, E. A., R. E. Olver, and L. B. Strang. 1975. Changes in nonelectrolyte permeability of alveoli and the absorption of lung liquid at the start of breathing in the lamb. J. Physiol. (Lond.). 244:161-179.

36. Jobe, A., M. Ikegami, H. Jacobs, S. Jones, and D. Conaway. 1983. Permeability of premature lamb lungs to protein and the effect of surfactant on that permeability. J. Appl. Physiol. 55:169-176.

37. Solimano, A., C. Bryan, A. Jobe, M. Ikegami, and H. Jacobs. 1985. Effects of high-frequency and conventional ventilation on the premature lamb lung. J. Appl. Physiol. 59:1571-1577.

38. Ikegami, M., A. H. Jobe, D. D. Berry, T. ElKady, A. Pettenazzo, and S. Seidner. 1987. Effects of distention of the preterm fetal lamb lung on lung function with ventilation. Am. Rev. Respir. Dis. In press. 